\title{
Erratum to: Distortions of Robertson-Walker metric in perturbative cosmology and interpretation as dark matter and cosmological constant
}

\author{
Federico $\mathbf{R e}^{1,2, \mathrm{a}}$ \\ ${ }^{1}$ DiSAT, Insubria University, Via Valleggio 11, Como, Italy \\ ${ }^{2}$ INFN, via Celoria 16, 20133 Milan, Italy
}

Received: 12 January 2021 / Accepted: 31 January 2021 / Published online: 8 February 2021

(C) The Author(s) 2021

\section{Erratum to: Eur. Phys. J. C (2020) 80:158 https://doi.org/10.1140/epjc/s10052-020-7713-4}

This erratum concerns the corrections of Equation (41), that should read:

$$
\langle A\rangle(\tau)=4 \pi\left(\frac{1}{3} \mathcal{N}(n / \sqrt{3})-\frac{1}{n^{2}}\right) \frac{G\left\langle\tilde{\rho}_{0}\right\rangle}{H_{0}^{2}} a(\tau)^{n-1},
$$

and Equation (44), that should read:

$\mathcal{N}(n)=\frac{1}{n^{2}+1}-\frac{1}{n^{2}}, \quad \mathcal{M}(n)=\frac{1}{n^{2}-1}-\frac{1}{n^{2}}$.

These leads to corrections to subsequent Equations (45), (50), (51) and (53). The corrected formulas allows to evaluate the parameters as

$n \cong 0.6761, \quad \Omega_{I M 0} \cong 0.0402$,

which return a complete explanation of the dark matter $\Omega_{F M 0} \cong 0.272 \cong \Omega_{D M 0}$ and the dark energy $\Omega_{F \Lambda 0} \cong$ $0.685 \cong \Omega_{\Lambda 0}$.
The Equation (69) becomes

$\Omega_{F \Lambda}(t) \cong \begin{cases}\text { unknown } & \text { for } \mathbf{a}(t)<0.082 \\ 1 & \text { for } 0.082<\mathbf{a}(t)<0.867 . \\ 0.685 \cdot \mathbf{a}(t)^{-2.65} & \text { for } \mathbf{a}(t)>0.867\end{cases}$

Open Access This article is licensed under a Creative Commons Attribution 4.0 International License, which permits use, sharing, adaptation, distribution and reproduction in any medium or format, as long as you give appropriate credit to the original author(s) and the source, provide a link to the Creative Commons licence, and indicate if changes were made. The images or other third party material in this article are included in the article's Creative Commons licence, unless indicated otherwise in a credit line to the material. If material is not included in the article's Creative Commons licence and your intended use is not permitted by statutory regulation or exceeds the permitted use, you will need to obtain permission directly from the copyright holder. To view a copy of this licence, visit http://creativecomm ons.org/licenses/by/4.0/.

Funded by SCOAP 3 .

The original article can be found online at https://doi.org/10.1140/ epjc/s10052-020-7713-4.

a e-mail: fre@uninsubria.it (corresponding author) 